\title{
MORBIDADE DA DOENÇA DE CHAGAS EM ÁREAS DO SERTÃO DA PARAÍBA E DA CAATINGA DO PIAUÍ
}

\author{
José Rodrigues Coura, José Borges-Pereira, Francisco Itamar Alves Filho, \\ José Adail Fonseca de Castro, Rivaldo Venâncio da Cunha, Walfredo Costa \\ e Angela Cristina Veríssimo Junqueira
}

\begin{abstract}
Foram estudados 186 pares de indivíduos sorologicamente positivos e negativos para infecção chagásica, da mesma idade e sexo, do Sertão da Paraỉba e 200 indivíduos também sorologicamente positivos nos municípios de Oeiras e Colônia do Piauí. Depois de confirmados por pelo menos dois outros testes sorológicos: imunofluorescência indireta quantitativa, ELISA, hemaglutinação ou fixação do complemento, foi feitoo exame clínico, eletrocardiográfico e radiológico nos individuos selecionados para o estudo exenodiagnóstico, hemocultura e PCR em amostras representativas dos casos soropositivos. As manifestações clínicas predominantes entre os soropositivos em ambas as áreas foram palpitações, dispnéia aos esforços, disfagia, odinofagia, pirose e obstipação. As freqüências das alterações eletrocardiográficas sugestivas da doença de Chagas foram, respectivamente, na Paraiba e no Piaui: $B A V=3,8 \%$ e $2 \%$, $B R D I I I=6,4 \%$ e $7 \%, B R D I I I+H B A E=10,7 \%$ e $10,5 \%$ e extra-sistoles ventriculares complexas $=2,7 \%$ e 3,\% . Oxenodiagnóstico foi positivo em $13 \%$ dos casos soropositivos da Paraiba e em $34 \%$ dos casos do Piaui, enquanto que o PCR foi positivo, respectivamente, em 44,6 e 59,5\%. A hemocultura realizada apenas no Piaut foi positiva em $25,7 \%$ dos casos estudados. Foram realizados inquéritos triatomínicos em 132 domicílios e peridomicílios no Sertão da Paraiba e em 159 na Caatinga do Piaui, sendo capturados 16 exemplares de T. brasiliensis não infectados no peridomicilio na Paraiba e 750 exemplares no Piaui, dos quais 625 foram examinados: 49 de T. pseudomaculata não infectados com $\mathrm{T}$. cruzi 19 no intradomicílio e 30 no peridomicilio) e 576 de $\mathrm{T}$. brasiliensis ( 371 no intradomicílio e 205 no peridomicílio) entre os quais $32(5,5 \%$ ) estavam infectados com $\mathrm{T}$. cruzi (31 no intradomicílio e um no peridomicilio).
\end{abstract}

Palavras-chaves: Doença de Chagas. Morbidade. Trypanosoma cruzi. Nordeste do Brasil.

A morbidade da doença de Chagas está relacionada a uma série de fatores dependentes do parasita (cepas e clones do Trypanosoma cruzi), que condicionam o seu tropismo para diferentes órgãos e tecidos, de acordo com os seus receptores, da qualidade do vetor, principalmente do seu grau de

\footnotetext{
Departamento de Medicina Tropical do Instituto Oswaldo Cruz (FIOCRUZ), Rio de Janeiro, RJ e Departamento de Microbiologia e Parasitologia, Universidade Federal do Piauí, Teresina, PI.

Trabalho realizado com auxílio do Programa de Controle de Doenças Endêmicas do Nordeste (PCDEN), da Fundaçāo Nacional de Saúde, do Instituto Oswaldo Cruz (FIOCRUZ) e do Conselho Nacional de Desenvolvimento Científicoe Tecnológico (CNPq).

Enderego para correspondência: Prof. José Rodrigues Coura. Departamento de Medicina Tropical/FIOCRUZ. Av. Brasil 4365, Manguinhos, 21045-900 Rio de Janeiro, RJ.

Recebido para publicação em 16/01/96.
}

antropofilia, da capacidade de conversão do parasita em formas infectantes, da seleção de clones com maior ou menor patogenicidade, do tempo de evacuação do vetor após o repasto, da quantidade de parasitas eliminados, do prurido causado no local da picada, do inóculo nas infecções e reinfecções e do tipo de resposta do hospedeiro infectado com maior ou menor adaptação à infecção, da resistência e da imunidade e de fatores de auto-imunidade e auto-agressão ainda pouco conhecidos ${ }^{13}$.

As diferenças regionais da morbidade da doença são certamente dependentes dos fatores acima mencionados e estão amplamente documentadas em trabalhos de diversos autores e revistas em reuniões sobre o assunto ${ }^{26}$. Nos últimos 20 anos, temos estudado comparativamnte a morbidade da doença de Chagas em quatro áreas de campo em Minas 
Coura JR. Borges-Pereira J, Alves Filho FI, Castro JAF, Cunha RV, Costa W, Junqueira ACV. Morbidade da doença de Chagas em áreas do Sertão da Paraiba e da Cautinga do Piaut. Revista da Sociedade Brasileira de Medicina Tropical 29:197-205, mar-abr, 1996.

Gerais, Paraíba e Piauí ${ }^{15} 2425$.

$$
\text { Os primeiros estudos clínicos e }
$$
epidemiológicos sobre a doença de Chagas na Paraiba foram realizados na década de 50 e 60 por Carvalho $^{78}$. Na mesma época, Lucena e Costa ${ }^{19}$ chamaram a atenção para a presença de Triatoma brasiliensis e pseudomaculata como vetores da infeç̧ão no Sertão daquele Estado e Lucena e Dantas $^{20}$ descreveram o primeiro caso agudo da doença em uma criança de 11 anos procedente de Teixeira na mesma região. Posteriormente, chamamos a atenção para a benignidade da doença em pacientes procedentes daquele Estado ${ }^{12} 14 \mathrm{em}$ comparação com outros procedentes da Bahia e de Minas Gerais, o que foi confirmado pelo inquérito eletrocardiográfico nacional realizado por Macedo e cols ${ }^{21}$. Arruda $\mathrm{Jr}^{2}$ e Arruda $\mathrm{Jr}$ e cols ${ }^{3}$ estudaram aspectos da morbidade da doença em três municípios do Vale do Piancó, no Sertão da Paraíba. Pereira e Coura ${ }^{24}$ e Pereira e cols ${ }^{25}$ vêm estudando desde 1984, a morbidade e a evolução da doença de Chagas em 8 municípios do Sertão da Paraíba. Finalmente, Shikanai-Yasuda e cols ${ }^{29}$ descreveram um surto da doença de Chagas aguda, possivelmente por transmissão oral em Catolé do Rocha, também, no Sertão da Paraíba.

A primeira referência à doença de Chagas no Piauí, deve-se a Neiva e Pena ${ }^{22}$, que em viagem realizada em 1912, pelos Estados da Bahia, Pernambuco, Piauí e Goiás, observaram casos de entalo e de vexame do coração em São Raimundo Nonato e Caracol e descreveram a presença de Triatoma brasiliensis, maculata e sordida no Sul daquele Estado. Posteriormente, foram descritos no Rio de Janeiro casos naturais ou procedentes do Piaur $^{4} 1214$. Entretanto, somente a partir de 1975, com os estudos de Figueiredo e cols ${ }^{1617}$, CorreiaLima $^{9}$ e Correia-Lima e cols ${ }^{10}$, foram feitos estudos sistematizados sobre a doença naquela região. Recentemente, Alves Filho' reestudou a morbidade da doença de Chagas nos municípios de Oeiras e Colônia do Piauí.

O presente trabalho visa uma reavaliação da doença de Chagas em áreas estudadas no Sertão da Paraiba e na Caatinga do Piauí.

\section{MATERIAL E MÉTODOS}

O estudo foi realizado na população residente na sede dos municípios de Piancó, Olho D'Água, Catingueira, São José de Caiana, Emas, Mãe D’Água, Água Branca e Imaculada, localizados no Serião da Paraíba e nos povoados de São Miguel. Curral Velho e Boa Vista pertencentes ao município de Oeiras, na sede e localidades circunvizinhas do município de Colônia do Piauí e nos povoados de Angical e Oitis pertencentes a esse município, localizados na região da Caatinga do Piauí (Figura1).

\section{Prevalência da infecção}

Na Paraíba foram colhidas aleatoriamente 5137 amostras de sangue em papel de filtro, após punção da polpa digital de $34,7 \%$ das pessoas residentes na sede dos municípios mencionados, enquanto no Piauí foram colhidas com a mesma técnica 4212 amostras de sangue, representando $73,6 \%$ da população residente nos povoados e uma amostra de 47,1\% na sede e localidades circunvizinhas do município de Colônia do Piauí.

Todas as amostras de sangue foram submetidas à reação de imunofluorescência indireta (IFI) de acordo com a técnica de Souza e Camargo ${ }^{30}$ e posteriormente confirmadas por pelo menos duas reações sorológicas, entre as quais a imunofluorescência quantitativa no soro, ELISA, hemaglutinação ou reação de fixação do complemento, visando o estudo clínico, eletrocardiográfico e radiológico.

\section{Estudo clínico e eletrocardiográfico}

Foram estudados do ponto de vista clínico e eletrocardiográfico, 186 pares com sorologia positiva e negativa do mesmo sexo e idade nas áreas do Sertão da Paraíba e 200 pacientes com sorologia positiva nas áreas da Caatinga do Piauí.

Foram utilizados dois questionários, um para anotação do inquérito pessoal e domiciliar, inclusive a presença e o contacto dos indivíduos com triatomíneos e outro para a anamnese e o exame físico. O exame clínico foi dirigido para os aparelhos cardiovascular e digestivo e o eletrocardiograma foi realizado com as 12 derivações clássicas, periféricas 
Coura JR, Borges-Pereira J, Alves Filho FI, Castro JAF, Cunha RV, Costa W, Junqueira ACV. Morbidade da doença de Chagas em áreas do Sertão da Paraiba e da Caatinga do Piauí. Revista da Sociedade Brasileira de Medicina Tropical 29:197-205, mar-abr, 1996.

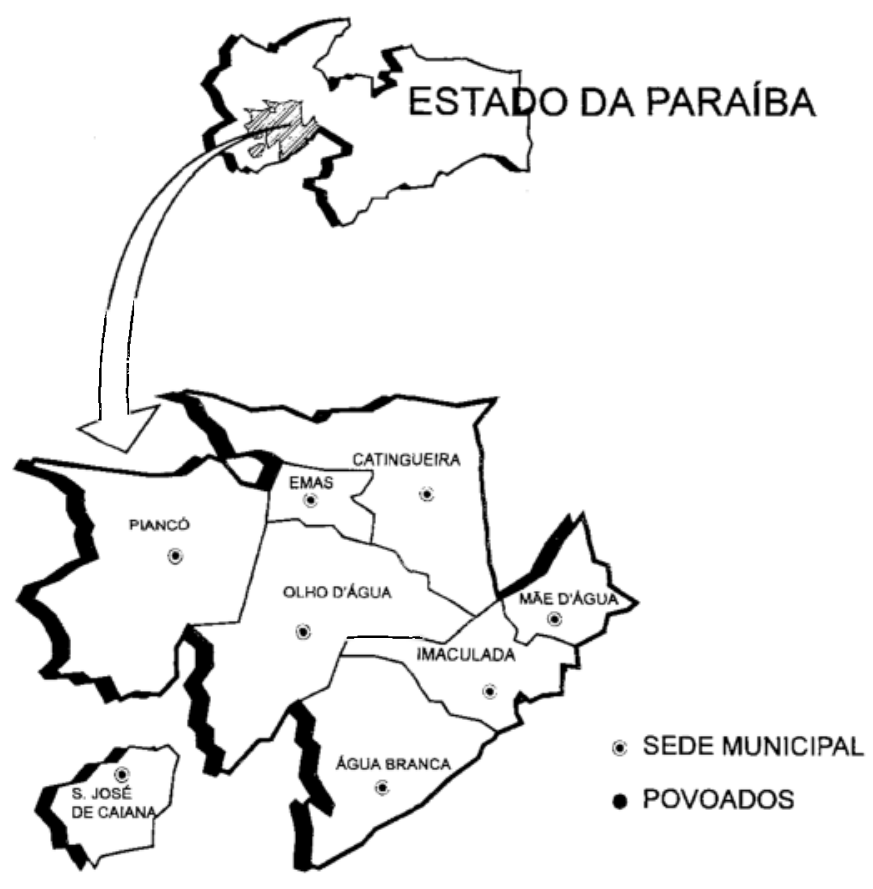

SERTÃO DA PARAÍBA

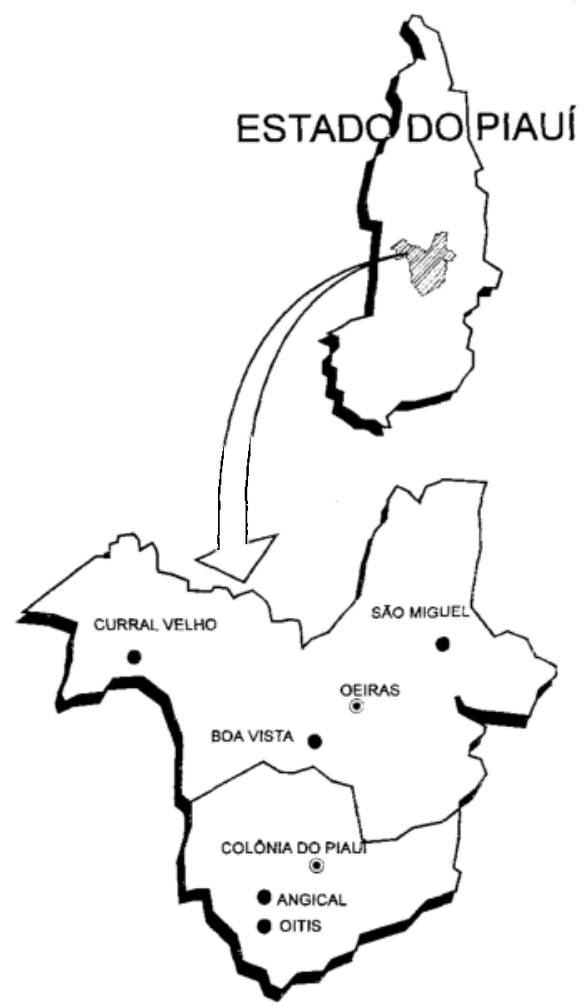

CAATINGA DO PIAUI

Figura 1 - Localização das áreas nos Estados da Paraiba e do Piauí.

e precordiais, com pelo menos três complexos por derivação e D2 longo em caso de arritmia. A interpretação do eletrocardiograma foi feita de acordo com os critérios da New York Heart Association $^{23}$, considerando-se, entretanto, as freqüências entre 60 e $120 \mathrm{cpm}$ como normais, a fim de compará-lo com estudo anteriormente realizado nas referidas áreas utilizando-se o mesmo critério.

\section{Estudo radiográfico}

Nas áreas do Sertão da Paraíba foram realizadas abreugrafias de $70 \mathrm{~mm}$ em ântero-posterior e perfil do tórax com esôfago contrastado dos pares sorologicamente positivos e negativos nos tempos zero e um minuto após a ingestão do contraste, de acordo com o método preconizado por Rezende e cols $^{27}$, enquanto na Caatinga do Piauí foram realizadas telerradiografias nos pacientes nas mesmas posições e ainda radiografias com esôfago contrastado em perfil nos indivíduos com disfagia ou odinofagia. A classificação radiológica da esofagopatia foi feita de acordo com Rezende e $\operatorname{cols}^{28}$.

\section{Xenodiagnóstico}

Em uma amostra de 54 pacientes do Sertão da Paraíba e 120 da Caatinga do Piauí, representando respectivamente, 29 e $60 \%$ dos casos com sorologiá positiva, foi feito o xenodiagnóstico empregandose ninfas de $3^{\circ}$ ou $4^{\circ}$ estádios, 20 de $T$. infestans e 20 outras de $P$. megistus. As ninfas foram divididas em 4 caixas com 10 triatomíneos em cada uma, colocadas duas caixas na face interna de cada um dos antebraços dos pacientes, deixando-as durante 30 minutos. Os triatomíneos foram realimentados com sangue de galinha no $23^{\circ}$ dia e a leitura de cada ninfa foi feita no $45^{\circ}$ dia após o repasto inicial, através da observação microscópica das fezes obtidas por compressão abdominal ou do tubo digestivo triturado em PBS 7.2 quando as fezes eram negativas. 
Coura JR, Borges-Pereira J, Alves Filho Fl, Castro JAF, Cunha RV, Costa W, Junqueira ACV. Morbidade da doença de Chagas em áreas do Sertão da Paraíba e da Caatinga do Piaui. Revista da Sociedade Brasileira de Medicina Tropical 29:197-205, mar-abr, 1996.

\section{Hemocultura}

Em 101 pacientes, da Caatinga do Piauí (50\% dos casos com sorologia positiva), foram colhidos $30 \mathrm{ml}$ de sangue por punção venosa, o qual era centrifugado, retirado o plasma sobrenadante e o sedimento depois de lavado (centrifugado) com meio LIT ( Liver Infusion Tryptose ) era dividido em partes iguais e plantado em 5 tubos contendo $4 \mathrm{ml}$ de meio LIT. A leitura foi feita aos 45, 60, 90 e 120 dias após a semeadura.

\section{Reação da polimerase em cadeia (PCR)}

Foram colhidos $7 \mathrm{ml}$ de sangue de 172 indivíduos no Sertão da Paraíba, 87 com sorologia positiva e 85 com sorologia negativa, enquanto na Caatinga do Piauí foi colhida a mesma quantidade de sangue para realização do PCR em 101 individuos com sorologia positiva para infecção chagásica. O PCR foi realizado em ambos os grupos de acordo com as técnicas aplicadas por Britto e cols ${ }^{5}{ }^{6}$, Wincker e $\operatorname{cols}^{31}$ e Junqueira e cols ${ }^{18}$.

\section{Inquérito triatomínico}

Foi realizado um inquérito triatomínico em uma amostra aleatória de 132 domicílios e peridomicílios no Sertão da Paraíba e 159 na região da Caatinga do Piauí, onde existiam indivíduos com sorologia positiva para a infecção chagásica. Com o auxílio de guardas da Fundação Nacional de Saúde foi feita a busca de triatomíneos após a aplicação do desalojante 'piriza' no intradomicílio, nas paredes, atrás de quadros, papéis e outros objetos, nas camas e colchões ou em qualquer outro lugar onde eles pudessem sealojar. No peridomicílio foram pesquisados galinheiros, chiqueiros, estacas, madeiras, tijolos ou pedras empilhados ou quaisquer outros possíveis abrigos. Foram considerados positivos os domicílios ou peridomicílios onde foram capturados triatomíneos vivos. Vestígios como fezes, parte de insetos ou mesmo exúvias, não eram considerados como positividade neste inquérito. Os triatomíneos capturados eram colocados em caixas apropriadas, classificados e examinados na busca do Trypanosoma cruzi.

\section{RESULTADOS}

\section{Prevalência da infecção}

As prevalências sorológicas da infecção chagásica por localidade estão expressas na Tabela 1, referente ao Sertão da Paraíba e na Tabela 2, relativa a localidades estudadas na Caatinga do Piauí, mostrando respectivamente uma prevalência global de $9,5 \%$ e $5,9 \%$ de reações sorológicas positivas. Na Paraíba, a prevalência da infecção foi de $7,8 \%$ no sexo masculino e de $10,5 \%$ no sexo feminino, enquanto no Piauí, foi de $6,4 \%$ para o sexo masculino e $5,5 \%$ para o feminino.

Tabela 1 - Prevalência sorológica (IFI) da infecção chagásica no Sertão da Paraiba.

\begin{tabular}{lccc}
\hline $\begin{array}{c}\text { Municípios } \\
\text { (sede) }\end{array}$ & $\begin{array}{c}\text { Amostras } \\
\text { exami- } \\
\text { nadas }\end{array}$ & $\begin{array}{c}\text { Amostras } \\
\text { posi- } \\
\text { tivas }\end{array}$ & $\begin{array}{c}\% \text { Amos- } \\
\text { tras } \\
\text { positivas }\end{array}$ \\
\hline Piancó & 2.063 & 181 & 8,8 \\
Olho D'Água & 681 & 111 & 16,3 \\
Catingueira & 582 & 47 & 8,1 \\
São José de Caiana & 556 & 37 & 6,7 \\
Emas & 264 & 27 & 10,0 \\
Mãe D'Água & 207 & 21 & 10,1 \\
Água Branca & 484 & 38 & 7,8 \\
Imaculada & 300 & 27 & 9,0 \\
\hline Total & 5.137 & 489 & 9,5 \\
\hline
\end{tabular}

Tabela 2 - Prevalência sorológica (IFI) da infecção chagásica na Caatinga do Piauí.

\begin{tabular}{lrrr}
\hline \multicolumn{1}{c}{$\begin{array}{c}\text { Municípios } \\
\text { (localidades) }\end{array}$} & $\begin{array}{c}\text { Amostras } \\
\text { exam- } \\
\text { inadas }\end{array}$ & $\begin{array}{c}\text { Amostras } \\
\text { posi- } \\
\text { tivas }\end{array}$ & $\begin{array}{c}\text { Amos- } \\
\text { tras } \\
\text { positivas }\end{array}$ \\
\hline $\begin{array}{l}\text { Colônia (sede) e Io- } \\
\text { calidades circunvi- }\end{array}$ & & & \\
zinhas & 2.312 & 121 & 5,2 \\
$\quad$ Oitis & 755 & 77 & 10,2 \\
$\quad$ Angical & 179 & 8 & 4,4 \\
Oeiras & & & \\
$\quad$ São Miguel & 704 & 33 & 4,6 \\
$\quad$ Boa Vista & 80 & 2 & 2,5 \\
$\quad$ Curral Velho & 182 & 10 & 5,5 \\
\hline Total & 4.212 & 251 & 5,9 \\
\hline
\end{tabular}

IFI = imunofluorescência indireta 
Coura JR, Borges-Pereira J, Alves Filho FI, Castro JAF, Cunha RV, Costa W, Junqueira ACV. Morbidade da doença de Chagas em áreas do Sertão da Paraiba e da Caatinga do Piauí. Revista da Sociedade Brasileira de Medicina Tropical 29:197-205, mar-abr, 1996.

Com referência à idade, a prevalência da infecção foi crescente na Paraíba até a quarta década da vida, estabilizando-se a partir de então, enquanto no Piauí, ela foi crescente até a sexta década.

\section{Estudo clínico e eletrocardiográfico}

A distribuição dos grupos de estudo por faixa etária e sexo consta da Tabela 3.

As manifestações clínicas predominantes no grupo soropositivo para a infecção chagásica tanto na Paraíba como no Piauí foram as palpitações, a dispnéia aos esforços, a dor precordial, a disfagia, odinofagia, pirose e a obstipacão intestinal.

Quanto às alterações eletrocardiográficas sugestivas da doença de Chagas, encontramos na Paraíba o bloqueio completo do ramo direito associado ao hemibloqueio anterior esquerdo em $10,7 \%$ dos casos, o bloqueio completo do ramo direito isolado em $6,4 \%$, o bloqueio aurículoventricular em $3,8 \%$ e as extra-sístoles ventriculares complexas (múltiplas e polifocais) em 2,7\%, enquanto no Piauí, estas alterações foram encontradas respectivamente em $10,5 \%, 7 \%, 2 \%$ e $3 \%$ dos casos, não havendo portanto diferença significativa (Tabela 4).

\section{Estudo radiográfico}

Nos casos estudados no Sertão da Paraíba não foi encontrada cardiomegalia em nenhum deles. Apenas em duas mulheres soropositivas, com $56 \mathrm{e}$ 59 anos de idade, e alterações eletrocardiográficas sugestivas da doença de Chagas, observou-se megaesôfago do grupo I, de acordo com a classificação de Rezende e $\operatorname{cols}^{28}$. Já no Piauí, foram verificados 35 casos com cardiomegalia, representando $17,5 \%$ dos casos estudados, $20(10 \%)$ no sexo masculino e $15(7,5 \%)$ no sexo feminino. Em 44 casos sintomáticos, com disfagia e/ou odinofagia submetidos à radiografia do esôfago no Piauí, $22(50 \%)$ foram normais, $8(18,1 \%)$ apresentaram megaesôfago grupo I, $2(4,5 \%)$ do grupo II, $2(4,5 \%)$ do grupo III e um $(2,2 \%)$ do grupo IV; 9 exames foram considerados inconclusivos.

\section{Xenodiagnósticos}

Em 54 casos com sorologia positiva para a infecção chagásica, submetidos ao xenodiagnóstico na Pararba, $7(13, \%)$ foram positivos, enquanto no Piauí, de 120 casos submetidos a este exame, 41 (34\%) foram positivos. Dos 7 casos com xenodiagnósticos positivos na Paraíba, $2(10 \%)$ eram do sexo masculino e 5 (15\%) do sexo feminino, enquanto dos 41 positivos no Piauí, 27 (40,9\%) eram do sexo masculino e 14 (25,9\%) do sexo feminino; 31 dos 41 casos com xenodiagnósticos positivos no Piauí, ou seja mais de $75 \%$, tinham mais de 40 anos de idade, representando naturalmente a população estudada.

\section{Hemocultura}

A hemocultura, realizada em 101 pacientes com sorologia positiva para a infecção chagásica escolhidos aleatoriamente entre os casos da região

Tabela 3 - Distribuição por faixa etária e sexo dos grupos de estudo com sorologia positiva para infecção chagásica no Sertão da Paraiba e na Caatinga do Piauí.

\begin{tabular}{|c|c|c|c|c|c|c|c|c|c|c|}
\hline \multirow{3}{*}{ Faixa etária } & \multicolumn{4}{|c|}{ Sertão da Paraîba } & \multicolumn{4}{|c|}{ Caatinga do Piauí } & & \\
\hline & \multicolumn{2}{|c|}{ masculino } & \multicolumn{2}{|c|}{ feminino } & \multicolumn{2}{|c|}{ masculino } & \multicolumn{2}{|c|}{ feminino } & \multicolumn{2}{|c|}{ Total } \\
\hline & $n^{0}$ & $\%$ & $n^{0}$ & $\%$ & $\mathrm{n}^{\mathrm{o}}$ & $\%$ & $\mathrm{n}^{0}$ & $\%$ & $n^{0}$ & $\%$ \\
\hline $0-10$ & 0 & - & 0 & - & 1 & 0,9 & 1 & 1,1 & 2 & 0,5 \\
\hline $11-20$ & 5 & 2,6 & 5 & 2,6 & 0 & - & 0 & - & 10 & 2,6 \\
\hline $21-30$ & 6 & 3,2 & 18 & 9,6 & 2 & 1,8 & 6 & 6,5 & 32 & 8,3 \\
\hline $31-40$ & 7 & 3,7 & 17 & 9,1 & 18 & 16,6 & 17 & 18,4 & 59 & 15,2 \\
\hline $41-50$ & 22 & 11,8 & 33 & 17,7 & 40 & 37,0 & 23 & 25,0 & 118 & 30,5 \\
\hline$>50$ & 22 & 11,8 & 51 & 27,4 & 47 & 43,5 & 45 & 19,0 & 165 & 42,7 \\
\hline Total & 62 & 33,3 & 124 & 66,7 & 108 & 54,0 & 92 & 46,0 & 386 & 100,0 \\
\hline
\end{tabular}


Coura JR, Borges-Pereira J, Alves Filho FI, Castro JAF, Cunha RV, Costa W, Junqueira ACV. Morbidade da doença de Chagas em áreas do Sertão da Paraiba e da Caatinga do Piauí. Revista da Sociedade Brasileira de Medicina Tropical 29:197-205, mar-abr, 1996.

Tabela 4 - Frequiência das alterações eletrocardiográficas sugestivas da miocardiopatia chagásica crônica em áreas endêmicas do Sertão da Paraiba e na Caatinga do Piauí.

\begin{tabular}{|c|c|c|c|c|c|}
\hline \multirow{2}{*}{$\begin{array}{c}\text { Alterações } \\
\text { eletrocar- } \\
\text { diográficas }\left(^{*}\right)\end{array}$} & \multicolumn{2}{|c|}{$\begin{array}{c}\text { Paraiba } \\
(\mathrm{N}=186)\end{array}$} & \multicolumn{2}{|c|}{$\begin{array}{c}\text { Piauí } \\
(\mathrm{N}=200)\end{array}$} & \multirow{2}{*}{$p<0,05$} \\
\hline & $n^{0}$ & $\%$. & $n^{0}$ & $\%$ & \\
\hline $3 \mathrm{AV}$ & 7 & 3,8 & 7 & 3,8 & não \\
\hline BRD III & 12 & 6,4 & 12 & 6,4 & não \\
\hline BRD III + HBAE & 20 & 10,7 & 20 & 10,7 & não \\
\hline EV complexas & 5 & 2,7 & 5 & 2,7 & não \\
\hline
\end{tabular}

(*) o mesmo paciente pode ter mais de uma alteração

da Caatinga do Piauí, foi positiva em $26(25,7 \%)$ casos. Dos 26 casos com hemocultura positiva, 18 $(33,9 \%)$ eram do sexo masculino e $8(18,6 \%)$ do sexo feminino; 20 (76,9\%) desses 26 casos tinham mais de 40 anos de idade, refletindo a distribuição da população estudada.

\section{Reação da polimerase em cadeia (PCR)}

A reação da polimerase em cadeia (PCR), realizada por amplificação do K-DNA do $T$. cruzi no sangue de 101 pacientes da Caatinga do Piauí, os mesmos submetidos à hemocultura, foi positiva em $60(59,4 \%)$; destes, $35(58,3 \%)$ eram do sexo masculino e $25(41,6 \%)$ eram do sexo feminino. Esta mesma reação foi positiva em $21(44,7 \%)$ dos 47 pacientes soropositivos do Sertão da Paraíba estudados.

\section{Inquérito triatomínico}

No Sertão da Paraíba foram capturados 16 exemplares de $T$. brasiliensis em peridomicilio, nenhum deles infectado com $T$. cruzi, enquanto na Caatinga do Piauí, foram capturados 750 triatomíneos, dos quais 625 foram examinados: 49 de $T$. pseudomaculata, não infectados com T. cruzi (19 no intradomicílio e 30 no peridomić́lio) e 576 de $T$. brasiliensis (371 no intradomicílio e 205 no peridomicílio) entre os quais, $32(5,5 \%)$ infectados com $T$. cruzi ( 31 no intradomicílio e um no peridomicílio).

\section{DISCUSSÃO}

O primeiro aspecto a ser discutido no presente trabalho, e que logo de início chama nossa atenção, é a baixa prevalência da infecção chagásica nos menores de 10 anos, tanto no Sertão da Paraíba como na Caatinga do Piauí. No Sertão da Paraíba, nenhum caso foi observado naquela faixa etária, portanto, podemos considerá-la com prevalência zero; este fato ganha maior importância se considerarmos que a pouco mais de dez anos Pereira e Coura ${ }^{24} \mathrm{em}$ trabalho realizado entre novembro de 1984 e janeiro de 1985, encontraram uma prevalência sorológica para infecção chagásica de $3,4 \%$ neste grupo etário na mesma casuística, hoje incorporado a faixa de 11 a 20 anos, que apresenta prevalência atual de $5,3 \%$ (Tabelas 1,2 e 3 ) e apresentava naquela época $5,7 \%$; portanto, praticamente não houve aumento desde então. Por outro lado, na Caatinga do Piauí, encontramos apenas dois $(0,5 \%)$ casos na faixa etária de zero a 10 anos e nenhum caso na taixa de 11 a 20 anos, enquanto Correia-Lima $(1976)^{9}$, há 20 anos, na mesma área, encontrava uma prevalência de $1 \% \mathrm{e}$ $5,7 \%$, respectivamente, para indivíduos de 2 a 9 anos e de 10 a 19 anos de idade. Acresce ainda, que os dois casos sorologicamente positivos, na faixa de zero a 10 anos de idade, são fillhos de mães chagásicas, não se podendo excluir a possibilidade de transmissão congênita. Estes fatos apontam claramente para o controle da transmissão da infecção nas áreas mencionadas, apesar da irregularidade da borrificação das casas com inseticidas pela SUCAM-FNS nas últimas duas décadas.

As manifestaçōes clínicas e eletrocardiográficas nas duas áreas estudadas foram semelhantes, exceto as manifestações digestivas relacionadas à disperistalsis do esôfago, como a disfagia e a odinofagia que aparecem em $44(22 \%)$ casos na área da Caatinga do Piauí, confirmada radiologicamente em $13(6,5 \%)$ casos, $8(4 \%)$ casos com megaesôfago grupo I, 2 (1\%) com megaesôfago do grupo II, outros 2 ( $1 \%$ ) do grupo III e um $(0,5 \%)$ do grupo IV, enquanto na Paraíba, apenas dois $(1,1 \%)$ casos em 186 estudados foram confirmados com megaesôfago do grupo I. 
Coura JR, Borges-Pereira J, Alves Filho FI, Castro JAF, Cunha RV, Costa W, Junqueira ACV. Morbidade da doença de Chagas em áreas do Sertão da Paraiba e da Caatinga do Piaui. Revista da Sociedade Brasileira de Medicina Tropical 29:197-205, mar-abr, 1996.

A cardiomegalia observada com maior freqüência na Caatinga do Piauí está ocorrendo, provavelmente, devido a hipertensão arterial detectada em $16,3 \%$ dos casos contra $7,5 \%$ no Sertão da Paraíba $(\mathrm{p}<0,05)$.

O xenodiagnóstico foi positivo em apenas 7 (13\%) de 54 exames realizados no Sertãoda Paraíba, enquanto no Piauí de 120 exames realizados, 41 $(34,1 \%)$ foram positivos, mostrando uma maior adaptação das amostras de $T$. cruzi ao homem e aos triatomíneos empregados nos exames no Piauí. Em 115 xenodiagnósticos realizados por Correia-Lima $(1976)^{9}$ na área, 100 com $R$. prolixus, $11 \operatorname{com} T$. brasiliensis e 4 com $T$. infestans foi obtida uma positividade, respectivamente de $12 \%, 72,7 \%$ e $50 \%$ dos casos examinados, média de $19,1 \%$ de positividade, mostrando uma grande variação de acordo com a espécie de triatomíneo utilizada. Entretanto, Costa-Bento (1978) ${ }^{11}$ reexaminando 18 pacientes desta casuística de Correia-Lima, através de um estudo bem controlado, com 6 xenodiagnósticos consecutivos, obteve positividade em 17 (94,4\%), maior proporcionalmente com $T$. brasiliensis do que com $T$. infestans.

A hemocultura realizada em 101 casos, com sorologia positiva para infeç̧ão chagásica na Caatinga do Piauí, mostrou uma positividade de $25,7 \%$, portanto com menor sensibilidade do que o xenodiagnóstico, enquanto o PCR realizado nos mesmos casos revelou uma positividade de $59,4 \%$, contra $44,6 \%$ de positividade em 47 casos examinados com esta técnica no Sertão da Paraíba, o que revela menor circulação do parasito ou de seu K-DNA nesta última área.

Diante dos resultados observados neste trabalho, podemos concluir: 1) que a morbidade cardiológica decorrente da doença de Chagas na população estudada nas duas áreas foi semelhante, devendo o maior índice de cardiomegalia observado na Caatinga do Piauí ser atribuído a maior frequiência de hipertensão arterial nesta área; 2) que a disperistalsis e o megaesôfago foram mais freqüentes na população estudada na Caatinga do Piauí do que no Sertão da Paraiba; 3) que a baixa freqüência ou ausência de sorologia positiva para infecção chagásica nos grupos etários de zero a 10 e 11 a 20 anos de idade, nas duas áreas, indicam o controle da transmissão da infecção por vetor, apesar da irregularidade da borrifação das casas com inseticida; 4) que há um maior risco de transmissão da infecção chagásica por vetor na Caatinga do Piauí, devido à freqüência de triatomíneos domiciliados e infectados pelo $T$. cruzi.

\section{SUMMARY}

A clinical and electrocardiographic case control study was carried out with 186 pairs of persons with positive and negative serology for $T$. cruzi infection from the Sertâo Paraba and in 200 seropositive cases from the region of Caatinga in the State of Piaui, North-eastern Brazil. The predominant clinical manifestations in seropositive cases in both areas were: palpitations, dyspnea on effort, precordial pain, dysphagia, odynophagia, pyrosis and intestinal constipation. The EKG abnormalities rates suggestive of chronic chagasic cardiopathy were respectively in Paraiba and Piaui: $A V$ block $3.8 \%$ and $2 \%, R B B B$ III $6.4 \%$ and $7 \%, R B B B I I I$ + LAB 10.7\% and $10.5 \%$, and multifocal extrasystoles $2.7 \%$ and $3 \%$. Xenodiagnosis in a sample of 54 seropositive individuals in the Sertão of Paraiba and in 120 in the Caating of Piaui was revealed $13 \%$ and $34 \%$ positive; PCR tests in a sample of 47 seropositives in Paraiba and 101 in Piaui revealed positives in $44.6 \%$ and $59.5 \%$ respectively. Blood culture in LIT media of 101 seropositive cases from the Caatinga of Piaut was positive for $\mathrm{T}$. cruzi in $25.7 \%$. A triatomine survey carried out in a sample of 132 domiciles and peridomiciles in the Sertâo of Paraiba and in a sample of 159 in the Caatinga of Piaui showed the following results: In Paraba, 16 specimens of $\mathrm{T}$. brasiliensis, not infected with T. cruzi, were captured. In Piaui, 750 triatomines were captured, of these 625 were examined: 49 were $\mathrm{T}$. pseudomaculata, not infected with $\mathrm{T}$. cruzi $(19$ in peridomiciles and 30 in the domiciles), and 576 were $\mathrm{T}$. brasiliensis $(371$ in the domiciles and 205 in the peridomiciles) and of this latter specie 32 (5.5\%) were infected with $\mathrm{T}$. cruzi (31 in the domiciles and one in the peridomicile).

Key-words: Chagas'disease. Morbidity. T. cruzi. North-eastern Brazil. 

doença de Chagas em áreas do Sertão da Paraiba e da Caatinga do Piaui. Revista da Sociedade Brasileira de Medicina Tropical 29:197-205, mar-abr, 1996.

\section{AGRADECIMENTOS}

Os autores agradecem: (1) a todos os funcionários dos Centros de Saúde dos Municípios envolvidos neste trabalho pela mobilização das populações e ajuda nos exames realizados nos pacientes; (2) a todos os guardas e motoristas da Fundação Nacional da Saúde, regionais de Campina Grande(PB) e Teresina(PI), que participaram da captura dos triatomíneos; (3) a Izeneide Barros de Araujo pelo apoio aos trabalhos de laboratório no campo; (4) aos técnicos Antonio Edmilson Castro e Júlio Cesar Miguel pela realização dos testes sorológicos; (5) as estagiárias Laura Cristina Santos, Rose Kelly Aguiar e Valéria dos Santos Celano pelo exame dos triatomíneos do campo e auxílio na leitura dos xenodiagnósticos e a bióloga Neide Carrara Fernandes e o técnico José de Souza Nogueira pela manutenção das amostras de T. cruzi isoladas. À equipe do Dr. Egler Chiari pelo auxílio na leitura das hemoculturas.

\section{REFERÊNCIAS BIBLIOGRÁFICAS}

1. Alves Filho FI. Morbidade da doença de Chagas em áreas endêmicas dos municípios de Oeiras e Colônia do Paiuí. Tese de Mestrado, Instituto Oswaldo Cruz/Fundação Oswaldo Cruz, 1995.

2. Arruda Jr ER. Estudo sobre a doença de Chagas nos municípios de Aguiar e Boqueirão dos Cochos, Vale do Piancó, Estado da Paraíba. Tese de Mestrado, Faculdade de Medicina da Univesidade Federal do Rio de Janeiro, Rio de Janeiro, 1981.

3. Arruda Jr ER, Silva SM, Mendonça MZG, Barros MA. Doença de Chagas. Estudo epidemiológico em Santana dos Garrotes, Vale do Piancó. Ciência, Cultura e Saúde (CCS) 6:43-46,1984.

4. Benchimol AB. O eletrocardiograma na miocardite chagásica crônica. Boletim da Academia Nacional de Medicina 133:9-52, 1962.

5. Britto C, Cardoso MA, Wincker P, Morel CM. A simple protocol for the physical cleavage of Trypanosoma cruzi kineplast DNA present in chronic Chagas'disease. Memórias Instituto Oswaldo Cruz 88:171-172, 1993.

6. Britto C, Cardoso MA, Ravel C, Santoro A, BorgesPereira J, Coura JR, Morel CM, Wincker P. Trypanosoma cruzi : Parasite delection and strain discriminationin chronic chagasic patients from North-eastern Brazil using PCR amplification of kineplast DNA and non-radioctive hybridization. Memórias do Instiluto Oswaldo Cruz 90 (Supl I) $: 122,1995$.

7. Carvalho SB. Moléstia de Chagas no Nordeste Brasileiro. Medicina 21:7-23, 1953.

8. Carvalho SB. Aspectos clínicos e epidemiológicos da doença de Chagas na Paraiba. Revista de Gastroenterologia do Nordeste 1:101-125, 1961 .

9. Correia-Lima FG. Doença de Chagas no município de Oeiras, Piauí. Estudo seccional nas localidades de Colônia e Oitis. Tese de Mestrado, Faculdade de Medicina da Universidade Federal do Rio de Janeiro, 1976.

10. Correia-Lima FG, Figueiredo PZ, Portella Nunes JN. Prevalência da infeç̧āo chagásica na população humana determinada pelo teste de imunofluorescência indireta em 24 municípios do Estado do Piauí. Revista da Sociedade
Brasileira de Medicina Tropical 10:17-24, 1976.

11. Costa-Bento DN. Estudo comparado de xenodiagnóstico com Triatoma brasiliensis e Triatoma infestans em chagásicos crônicos de uma área endêmica no Estado do Piauí (Oitis). Tese de Mestrado, Instituto de Ciências Biológicas da Universidade Federal de Minas Gerais, Belo Horizonte, 1978.

12. Coura JR. Contribuiçāo ao estudo da doença de Chagas no Estado da Guanabara. Tese de Livre Docência, Faculdade de Medicina da Universidade Federal do Rio de Janeiro, Rio de Janeiro, 1965.

13. Coura JR. Determinantes epidemiológicos da doença de Chagas no Brasil: a infecção, a doença e sua morbimortalidade. Memórias do Instituto Oswaldo Cruz 83(supl I):392-402, 1989.

14. Coura JR. Evolutive pattern in Chagas' disease and the life-span of Trypanosoma cruzi in human infection. American Trypanosomiasis Research. Proceedings of an International Meeting. PAHO/WHO, Washington. Science Public 318:378-383,1976.

15. Coura JR, Abreu LL, Dubois LEG, Coreira-Lima FG, Arruda Jr. ER. Willcox HPF, Petana W. Morbidade da doença de Chagas II. Estudos seccionais em quatro áreas de campo no Brasil. Memórias do Instiluto Oswaldo Cruz $79: 10$ l-124, 1984.

16. Figueiredo PZ, Correia-Lima FG, Portella Nunes JN. Doença de Chagas: primeiros casos autóctones no Estado do Piauí. Revista da Sociedade Brasileira de Medicina Tropical 9:105-107, 1975a.

17. Figueiredo PZ, Correia-Lima FG, Portella Nunes JN. Contribuição ao estudo da distribuição geográfica de triatomíneos no Estado do Piauí. Revista da Sociedade Brasileira de Medicina Tropical 9:197-202, 1975 b.

18. Junqueira ACV, Chiari E, Wincker P. Comparison of the polymerase chain with two classical parasitological methods for the diagnosis of Chagas' disease patients in Northeastern region of Brazil. Transaction of the Royal Society of Tropical Medicine and Hygiene 90:1996.

19. Lucena DT, Costa L. Epidemiologia da doença de Chagas na Paraba. Revista Brasileira de Malariologia e Doenças 
Coura JR, Borges-Pereira J, Alves Filho FI, Castro JAF, Cunha RV, Costa W, Junqueira ACV. Morbidade da doença de Chagas em áreas do Sertão da Paraiba e da Caatinga do Piauí. Revista da Sociedade Brasileira de Medicina Tropical 29:197-205, mar-abr, 1996.

Tropicais 6:229-265, 1954.

20. Lucena DT, Dantas M. Primeiro caso agudo da doença de Chagas na Paraiba. Revista Brasileira de Medicina 14:855857,1957

21. Macedo V, Prata A, Silva GR, Castitho E. Prevalência de alteraçōes eletrocardiográficas em chagásicos (Informaçōes preliminares sobre o inquérito eletrocardiográfico nacional). Arquivos Brasileiros de Cardiologia 38:261$264,1982$.

22. Neiva A Penna B. Viagem científica pelo Norte da Bahia, Sudoeste de Pernambuco, Sul do Piauhi e de Norte a Sul de Goiaz. Memórias do Institulo Oswaldo Cruz 8:74-224, 1916 .

23. New York Heart Association (NYHA). Nomenclature and criteria for diagnosis of disease of the heart and great vessels. $7^{\text {th }}$ Ed. Littleand Brown Company, Boston, 1973.

24. Pereira JB, Coura JR. Morbidade da doença de Chagas em populações urbanas do Sertão da Paraíba. Revista da Sociedade Brasileira de Medicina Tropical 20:101-107, 1987.

25. Pereira JB, Cunha RV, Willcox HPF, Coura JR. Evoluçāo da cardiopatia chagásica crônica humana no Sertão do Estado da Paraiba, no período de 4,5 anos. Revista da Sociedade Brasileira de Medicina Tropical 23:141-147, 1990.

26. Prata A. (Editor). Reunião sobre diferenças geográficas na doença de Chagas. Universidade de Brasília, Escopo Editora, Brasilia, DF, 1975

27. Rezende JM, Oliveira R, Lauar KM. Valor do tempo de esvaziamento esofagiano no diagnóstico da esofagopatia chagásica (prova de retenção). Revista Goiana de Medicina 5:97-102,1959.

28. Rezende JM, Oliveira R, Lauar KM. Aspectos clínicos e radiológicos da aperistalsis do esôfago. Revista Brasileira de Gastroenterologia 12:247-262,1960.

29. Shikanai-Yasuda MA, Marcondes CB, Guedes LA, Siqueira GS, Barone AA, Dias JCP, Amato Neto V. Tolezano JE, Peres BA, Arruda Jr MH, Lopes ER, Shiroma M, Chapadeiro E. Possible oral transmission of acute Chagas'disease in Brazil. Revista do Instituto de Medicina Tropical de São Paulo 33:351-357, 1991.

30. Souza SL, Camargo ME. The use of filter paper blood smear in the pratical fluorescent test for American Trypanosomiasis serodiagnosis. Revista do Instituto de Medicina Tropical de Sāo Paulo 8:255-258, 1966.

31. Wincker P, Britto C, Borges-Pereira J, Cardoso MA, Oelemann W, Morel CM. Use of simplified polymerase chain reaction procedure to detect Trypanosoma crezi in blood samples from chronic chagasic patients in a rural endemic area. The American Journal of Tropical Medicine and Hygiene 51:771-777,1994. 